\title{
TEMPERATURAS PARA GERMINAÇÃO DE SEMENTES DE Poecilanthe parviflora Bentham (FABACEAE - FABOIDEAE) ${ }^{1}$
}

\author{
JANE VALADARES ${ }^{2}$, RINALDO CÉSAR DE PAULA ${ }^{3}$
}

\begin{abstract}
RESUMO - Poecilanthe parviflora (coração-de-negro) é uma planta arbórea com potencial para uso em áreas degradadas e no paisagismo. Este trabalho teve por objetivo avaliar condições de temperatura para condução do teste de germinação para as sementes de . parviflora. Foram realizados dois experimentos paralelos. No experimento 1 foi utilizado o lote denominado de JABOTICABAL que foi submetido à germinação em diferentes temperaturas constantes $\left(10,15,20,25,30,35\right.$ e $\left.40{ }^{\circ} \mathrm{C}\right)$ e alternadas (20-30, 25-35 e 20-35 $\left.{ }^{\circ} \mathrm{C}\right)$, totalizando 10 tratamentos. No experimento 2 foram utilizados os lotes denominados de USM, SEMEX e JABOTICABAL que foram submetidos à germinação a $25^{\circ} \mathrm{C}$ e a $20-30^{\circ} \mathrm{C}$ com fotoperíodo de 12 horas, totalizando seis tratamentos. Em cada experimento, foram utilizadas quatro repetições de 25 sementes por tratamento. A protrusão da raiz primária (> 0,5 cm) foi adotada como critério para considerar a semente germinada. Foram analisados os seguintes parâmetros: porcentagem de germinação e de plântulas normais, índice de velocidade de germinação, comprimento de plântulas, matéria fresca e seca de plântulas. O delineamento estatístico utilizado foi o inteiramente casualizado e as médias foram comparadas pelo teste de Scott-Knott a 5\% de probabilidade. Concluiu-se que o teste de germinação pode ser conduzido a 25 e a $25-35{ }^{\circ} \mathrm{C}$, com fotoperíodo de 12 horas, por 21 dias.
\end{abstract}

Termos para indexação: sementes florestais, coração-de-negro, temperatura, qualidade fisiológica

\section{TEMPERATURES FOR GERMINATION OF Poecilanthe parviflora Bentham (FABACEAE - FABOIDEAE) SEEDS}

\begin{abstract}
Poecilanthe parviflora is a tree with a good potential for revegetation and ornamental purposes. The objective of this research was to determine the best temperatures for the germination test. The work took place during 2005 and was conducted at the UNESP, Campus de Jaboticabal, Jaboticabal, São Paulo state, Brazil. Two experiments were conducted, simultaneously. The first one used the lot termed JABOTICABAL that was submitted to the germination test under different constant temperatures of $10,15,20,25,30,35$, and $40^{\circ} \mathrm{C}$ and alternate temperatures of 20-30, 25-35, and 20-35 ${ }^{\circ} \mathrm{C}$. The second one used the lots termed USM, SEMEX and JABOTICABAL that were submitted to the constant temperatures of $25{ }^{\circ} \mathrm{C}$ and alternate temperatures of $20-30{ }^{\circ} \mathrm{C}$, at a photoperiod of 12 hours. Four replications of 25 seeds each were used for both experiments. Primary
\end{abstract}

${ }^{1}$ Submetido em 14/11/2007. Aceito para publicação em 06/06/2008. Parte
da Dissertação de Mestrado do primeiro autor apresentada ao Programa
de Pós-Graduação em Agronomia (Produção e Tecnologia de Sementes,
PPGA-PTS) da UNESP, Campus de Jaboticabal. ${ }^{2}$ Eng. Agra ${ }^{\text {. }}$ mestranda do
PPGA-PTS, UNESP, Campus de Jaboticabal, E-mail: jardimsantamartha@ hotmail.com. ${ }^{3}$ UNESP- Universidade Estadual Paulista, Campus de Jaboticabal, Professor do Depto. de Produção Vegetal, Bolsista do CNPq, PQ - 2, CEP 14884-900, Jaboticabal, SP, E-mail: rcpaula@fcav.unesp.br. 
root protrusion $(>0,5 \mathrm{~cm})$ was adopted as criterion of germination. The following parameters were evaluated: germination, speed germination index, seedling length, fresh matter and dry matter of seedlings. The experiment was set according to a completely random design and the means were compared through the Scott-Knott test at the 5\% level of probability. Either a constant temperature of $25{ }^{\circ} \mathrm{C}$ or the alternate temperatures of $25-35^{\circ} \mathrm{C}$ were found to be the best ones for the germination test.

Index terms: forest seeds, coração-de-negro, temperature, physiological quality

\section{INTRODUÇÃO}

Poecilanthe parviflora Bentham é denominada popularmente como canela-de-brejo, coração, coração-denegro, ipê-coração, jacarandá-de-mato-grosso, pau-ferro e pau-jantar. Ocorre naturalmente nos estados da Bahia, Goiás, Mato Grosso, Minas Gerais, Paraná, Rio Grande do Sul e São Paulo (Carvalho, 2003). Pertence à família Fabaceae sub-família Faboideae (Souza e Lorenzi, 2005). Espécie secundária tardia ou clímax exigente em luz (Pinto, 1997), pode ser recomendado com sucesso no paisagismo, particularmente útil para arborização de ruas e avenidas. Sua madeira é muito pesada, de alta resistência ao apodrecimento e ao ataque de cupins de madeira seca (Lorenzi, 1992). O coração-de-negro é uma planta invasora de pastagem via brotação das raízes, tornando-se praga de pastos; não sendo roçada, forma com outras espécies, verdadeiras capoeiras. Suas sementes não apresentam dormência e sua madeira é indicada para fabricação de móveis e carpintaria; na construção civil é usada como esquadrias, tacos e tábuas para assoalho, vigas, caibros e ripas; é empregada, também, em estruturas externas, como postes, dormentes, cruzetas, mourões e cercas. A lenha do coração-de-negro é de ótima qualidade, ardendo mesmo quando verde. Produz celulose para papel de baixa qualidade. Pode também ser recomendada para a recuperação de ecossistemas degradados (Carvalho, 2003).

A utilização de sementes de boa qualidade constitui fator determinante para o êxito do empreendimento florestal. O principal atributo da qualidade a ser considerado é a capacidade germinativa das sementes, pois, sem ela, a semente não tem valor para a semeadura, e dela também depende a qualidade das mudas e o sucesso de um reflorestamento.

A temperatura é um fator importante que afeta o comportamento germinativo das sementes. As sementes apresentam comportamento variável frente a esse fator, não havendo uma temperatura ótima e uniforme de germinação para todas as espécies. Em geral a temperatura é chamada de ótima quando ocorre o máximo de germinação, no menor tempo, e máxima e mínima quando a germinaçãoé zero. Acima e abaixo dos limites máximo e mínimo, respectivamente, pode ocorrer a morte das sementes. A faixa de 20 a $30^{\circ} \mathrm{C}$ mostra-se adequada para a germinação de grande número de espécies subtropicais e tropicais (Borges e Rena, 1993). À medida que a semente se deteriora fica mais exigente quanto às temperaturas. Ela passa a ter necessidades específicas para que a germinação ocorra.

A temperatura adequada para a germinação de sementes de espécies arbóreas nativas vem sendo determinada por alguns pesquisadores. Como exemplo, foram definidas como ótimas para germinação, a temperatura de $25{ }^{\circ} \mathrm{C}$ para sementes de Stevia rebaudiana Bert. (Randi e Felipe, 1981), as de 30 e $35{ }^{\circ} \mathrm{C}$ para sementes de Prosopis juliflora (Sw.) DC. (Perez e Moraes, 1990), e as de 25 e $30^{\circ} \mathrm{C}$ para sementes de Mabea fistulifera Mart. (Leal Filho e Borges, 1992).

Segundo Carvalho e Nakagawa (2000), a temperatura tem grande influência no processo germinativo, não só com relação à velocidade do mesmo, mas também na porcentagem de germinação das sementes.

A instalação de uma cultura geralmente é efetuada com base nos resultados do teste de germinação, realizado rotineiramente em laboratórios de análise de sementes. Este teste é um dos meios mais utilizados para se determinar o nível de qualidade das sementes. Sua condução segue instruções detalhadas apresentadas nas Regras para Análise de Sementes, editadas em diversos países, dentre os quais o Brasil (Brasil, 1992), e por organizações internacionais, como a International Seed Testing Association (ISTA) e a Association of Official Seed Analysts (AOSA). Os objetivos principais do teste de germinação dirigem-se à obtenção de informações para determinar o valor das sementes para semeadura, armazenamento e para comparação de diferentes lotes.

O objetivo deste trabalho foi avaliar condições de temperatura para condução do teste de germinação para sementes de Poecilanthe parviflora Bentham (coração-denegro). 


\section{MATERIAL E MÉTODOS}

O presente trabalho foi desenvolvido com sementes de coração-de-negro (Poecilanthe parviflora Bentham, Fabaceae - Faboideae), provenientes de três localidades:

a-A Usina São Martinho, no município de Pradópolis,

SP, lote denominado USM.

b-Sementes colhidas na área urbana e no Campus da UNESP em Jaboticabal, lote denominado de JABOTICABAL.

c-Sementes do Vale do Paraíba, adquiridas junto à SEMEX, em São Paulo, lote denominado de SEMEX.

Para o lote JABOTICABAL e USM, o beneficiamento constou da abertura dos frutos, colhidos nas árvores, para obtenção das sementes com a eliminação de sementes mal formadas e chochas; o outro lote foi obtido beneficiado.

Os testes de germinação foram conduzidos no Laboratório de Sementes de Plantas Hortícolas e Florestais do Departamento de Produção Vegetal, Faculdade de Ciências Agrárias e Veterinárias (FCAV), pertencente à Universidade Estadual Paulista (Unesp), Campus de Jaboticabal, SP.

Foram realizados dois experimentos, simultaneamente, utilizando-se 100 sementes (quatro repetições de 25 sementes) para cada tratamento, distribuídas em caixas de plástico tipo "gerbox" contendo como substrato papel de filtro umedecido com quantidade de água 2,5 vezes o peso do papel.

Noexperimento 1 foiutilizado oloteJABOTICABAL que foi submetido à germinação em temperaturas constantes de $10,15,20,25,30,35$ e $40^{\circ} \mathrm{C}$ e alternadas de $20-30,25-$ 35 e $20-35^{\circ} \mathrm{C}$, totalizando 10 tratamentos. No experimento 2 foram utilizados os três lotes de sementes (USM, SEMEX e JABOTICABAL) que foram submetidos à germinação a $25^{\circ} \mathrm{C}$ e a $20-30^{\circ} \mathrm{C}$, com foto período de 12 horas, totalizando seis tratamentos. No caso das temperaturas alternadas, o período luminoso correspondeu à temperatura mais elevada. Nos dois experimentos a duração do teste de germinação foi de 21 dias.

O número de sementes germinadas foi avaliado adotando-se o critério da protrusão da raiz primária (maior que $0,5 \mathrm{~cm}$ ). Ao final do experimento foram avaliados a porcentagem de germinação $(\% \mathrm{G})$, porcentagem de plântulas normais (PN) e o índice de velocidade de germinação (IVG), este último calculado conforme Maguire (1962). Determinou-se, ainda, o comprimento total de plântulas, utilizando-se das plântulas normais em cada tratamento e repetição. Os resultados foram expressos em cm.plântula-1 ${ }^{-1}$, com duas casas decimais. Também foi determinada a massa fresca das plântulas normais, as quais foram colocadas em sacos de papel e pesadas descontando o peso da embalagem; posteriormente, as plântulas normais foram colocadas para secar em estufa com circulação de ar aquecido $\left(60^{\circ} \mathrm{C}\right)$, por 24 horas. Após esse período as amostras foram retiradas da estufa e colocadas para esfriar em dessecador, sendo então pesadas em balança analítica com precisão de $0,001 \mathrm{~g}$. Determinou-se a matéria seca total das plântulas normais componentes, resultando no valor médio da matéria seca por plântula, expresso em g.plântula ${ }^{-1}$.

Para o experimento 1 foi utilizado o delineamento inteiramente casualizado com 10 tratamentos (10temperaturas para o lote JABOTICABAL) e quatro repetições de 25 sementes por tratamento. As médias foram comparadas pelo teste de Scott-Knott a 5\% de probabilidade. Adicionalmente, usando-se apenas os dados relativos às temperaturas constantes, procedeu-se ao ajuste de regressão polinomial de até $3^{\circ}$ grau para o estudo das temperaturas cardeais do processo germinativo. Para o experimento 2, também foi utilizado o delineamento inteiramente casualizado, no esquema fatorial $3 \times 2$ (três lotes e duas temperaturas), totalizando seis tratamentos, sendo as médias comparadas pelo teste Scott-Knott a 5\% de probabilidade.

\section{RESULTADOS E DISCUSSÃO}

Na Tabela 1 são apresentados os resultados da análise de variância para porcentagem de germinação (G), índice de velocidade de germinação (IVG), porcentagem de plântulas normais (PN), comprimento de plântula (CP), massa fresca (MF) e massa seca (MS) de plântulas obtidas de sementes de Poecilanthe parviflora, do lote JABOTICABAL, submetidas à germinação, em diferentes temperaturas. Houve efeito significativo $(\mathrm{P} \leq 0,01)$ da temperatura sobre as características avaliadas. Os coeficientes de variação experimental $(\mathrm{CV})$ foram relativamente altos, variando de $22,24 \%$ para $\mathrm{MS}$ a $39,31 \%$ para $\mathrm{PN}$, indicando alta variabilidade, o que tem sido normal para sementes de espécies arbóreas nativas, mesmo em condições de ambiente controlado.

Nas temperaturas de $10^{\circ} \mathrm{C}$ e $40^{\circ} \mathrm{C}$ não houve germinação. Na temperatura de $15^{\circ} \mathrm{C}$ observou-se pequena porcentagem de sementes com protrusão de raiz primária, não havendo, contudo, o desenvolvimento de plântulas normais. Nas demais temperaturas, a protrusão de raiz primária ocorreu de forma mais satisfatória, sendo que as mais adequadas considerandose este critério, foram as temperaturas constantes de 20 e $25^{\circ} \mathrm{C}$ e a temperatura alternada de $25-35^{\circ} \mathrm{C}$. O IVG e PN apresentaram os maiores valores nas temperaturas constantes de 25 e $30^{\circ} \mathrm{C}$ e na temperatura alternada de $25-35^{\circ} \mathrm{C}$. 
TABELA 1. Resumo da análise de variância e médias de germinação (G, \%), índice de velocidade de germinação (IVG), plântulas normais (PN, \%) e comprimento (CP, cm), massa fresca (MF, g.plântula $\left.{ }^{-1}\right)$ e massa seca (MS, g.plântula ${ }^{-1}$ ) de plântulas de Poecilanthe parviflora (lote JABOTICABAL), obtidas de sementes submetidas à germinação em diferentes temperaturas.

\begin{tabular}{|c|c|c|c|c|c|c|c|}
\hline \multirow{2}{*}{$\begin{array}{c}\text { Fontes de } \\
\text { Variação }\end{array}$} & \multicolumn{7}{|c|}{ Quadrados Médios } \\
\hline & GL & G & IVG & PN & $\mathrm{CP}$ & MF & MS \\
\hline Temperatura & 9 & $2487,289 * *$ & $2,7694 * *$ & $1742,267 * *$ & $42,2952 * *$ & $0,2178 * *$ & $0,0826 * *$ \\
\hline Erro & 30 & 70.3999 & 0.1125 & 86.8 & 1.5938 & 0.01199 & 0.002 \\
\hline Média & & 35 & 1.077 & 24 & 4.5245 & 0.3209 & 0.2019 \\
\hline $\mathrm{CV} \%$ & & 23.7 & 31.16 & 39.31 & 27.9 & 34.11 & 22.24 \\
\hline Temperaturas & & & & Média & & & \\
\hline $10^{\circ} \mathrm{C}$ & & $0 \mathrm{c}$ & $0,000 \mathrm{c}$ & $0 \mathrm{~d}$ & $0,00 \mathrm{c}$ & $0,000 \mathrm{c}$ & $0,000 \mathrm{c}$ \\
\hline $15^{\circ} \mathrm{C}$ & & $1 \mathrm{c}$ & 0,012 c & $0 \mathrm{~d}$ & $0,00 \mathrm{c}$ & 0,000 c & $0,000 \mathrm{c}$ \\
\hline $20^{\circ} \mathrm{C}$ & & $53 \mathrm{a}$ & $1,037 \mathrm{~b}$ & $15 \mathrm{c}$ & $5,69 \mathrm{~b}$ & 0,449 a & 0,269 a \\
\hline $25^{\circ} \mathrm{C}$ & & $62 \mathrm{a}$ & 1,962 a & 55 a & $7,68 \mathrm{a}$ & 0,526 a & 0,331 a \\
\hline $30^{\circ} \mathrm{C}$ & & $50 \mathrm{~b}$ & 2,068 a & $43 \mathrm{a}$ & $6,37 \mathrm{~b}$ & 0,498 a & 0,309 a \\
\hline $35^{\circ} \mathrm{C}$ & & $44 \mathrm{~b}$ & $1,367 \mathrm{~b}$ & $28 \mathrm{~b}$ & $6,27 \mathrm{~b}$ & 0,431 a & 0,278 a \\
\hline $40^{\circ} \mathrm{C}$ & & $0 \mathrm{c}$ & 0,000 c & $0 \mathrm{~d}$ & $0,00 \mathrm{c}$ & 0,000 c & 0,000 c \\
\hline $20-30^{\circ} \mathrm{C}$ & & $42 \mathrm{~b}$ & $0,995 \mathrm{~b}$ & $37 \mathrm{~b}$ & 7,49 a & 0,511 a & 0,309 a \\
\hline $25-35^{\circ} \mathrm{C}$ & & 57 a & 2,004 a & $46 \mathrm{a}$ & $7,20 \mathrm{a}$ & 0,522 a & 0,318 a \\
\hline $20-35^{\circ} \mathrm{C}$ & & $45 \mathrm{~b}$ & $0,995 \mathrm{~b}$ & $13 \mathrm{c}$ & $4,54 \mathrm{~b}$ & $0,272 \mathrm{~b}$ & $0,204 \mathrm{~b}$ \\
\hline
\end{tabular}

Médias seguidas por uma mesma letra não diferem entre si $(\mathrm{P}>0,05)$ pelo teste de Scott-Knott.

Nota-se que a $20^{\circ} \mathrm{C}$, mesmo com boa porcentagem de protrusão de raiz primária, houve baixa porcentagem de plântulas normais. De acordo com CARVALHO e NAKAGAWA (2000), a temperatura ótima varia conforme o processo fisiológico sendo que, por exemplo, para a velocidade de germinação o ótimo é sempre um pouco mais alto do que para o total de germinação. Ainda, de acordo com esses autores, temperaturas acima da ótima para o total de germinação aceleram a velocidade do processo, mas desorganizando-o de forma que o número de sementes que conseguem completa-lo vai caindo rapidamente.

Maiores valores de CP foram obtidos com 25, 20-30 e $25-35^{\circ} \mathrm{C}$. Para MF e MS de plântulas, os maiores valores foram verificados nas temperaturas de 20, 25, 30, 35, 20$30^{\circ} \mathrm{C}$ e $25-35^{\circ} \mathrm{C}$. Para estas duas características (MF e MS) verifica-se ampla faixa de temperatura em que os resultados foram satisfatórios, o que poderia ser explicada pela competição entre plântulas nos "gerbox". Mesmo nas temperaturas em que houve baixa porcentagem de plântulas normais, estas se desenvolveram atingindo mais massa fresca e seca, por estarem sujeitas a uma menor competição entre elas. De acordo com Nakagawa (1999), lotes com menor germinação tendem a apresentar maiores valores de massa seca de plântulas que lotes com germinação maior, talvez por usufruírem de maior espaço nas caixas de germinação.

Santos e Aguiar (2000) estudando a germinação de sementes de Sebastiana commersoniana constataram que a germinação foi máxima aos 14 dias, em temperatura alternada $\left(20-30^{\circ} \mathrm{C}\right)$. Em temperatura constante de $25^{\circ} \mathrm{C}$, a germinação aumentou gradativamente e atingiu o valor máximo apenas aos 28 dias após a semeadura. Kraemer et al. (2000), estudando a germinação de sementes de Tibouchina urvilleana, constataram maior velocidade e homogeneidade de germinação a $25^{\circ} \mathrm{C}$, diminuindo nas temperaturas acima 
e abaixo desta. Sob $10^{\circ} \mathrm{C}$, não ocorreu germinação. Alves et al. (2002) relatam que a temperatura de $25^{\circ} \mathrm{C}$ mostrou-se mais adequada para a condução do teste de germinação em sementes de Mimosa caesalpiniaefolia, independentemente do substrato utilizado. Araújo Neto et al. (2003) constataram que a temperatura constante de $25^{\circ} \mathrm{C}$ foi a mais adequada para a germinação das sementes de Acacia polyphylla.

Pela Figura 1, observa-se que as temperaturas ótima, máxima e mínima foram, respectivamente, de $28,45^{\circ} \mathrm{C}$, $39,92^{\circ} \mathrm{C}$ e $11,26^{\circ} \mathrm{C}$, para a porcentagem de germinação (protrusão da raiz primária); de $29,96^{\circ} \mathrm{C}, 39,66^{\circ} \mathrm{C}$ e $12,97^{\circ} \mathrm{C}$, para a produção de plântulas normais; de $29,94^{\circ} \mathrm{C}, 39,8^{\circ} \mathrm{C}$ e $12,47^{\circ} \mathrm{C}$, para o índice de velocidade de germinação; de $29,4^{\circ} \mathrm{C}, 39,99^{\circ} \mathrm{C}$ e $11,58^{\circ} \mathrm{C}$, para o comprimento de plântula; de $29,1^{\circ} \mathrm{C}, 39,95^{\circ} \mathrm{C}$ e $11,47^{\circ} \mathrm{C}$, para matéria fresca e de $29,3^{\circ} \mathrm{C}, 39,98^{\circ} \mathrm{C}$ e $11,54^{\circ} \mathrm{C}$, para matéria seca de plântula.

FIGURA 1. Porcentagem de germinação (G) e de plântulas normais (PN), índice de velocidade de germinação (IVG), e comprimento (CP), massa de matéria fresca (MF) e seca (MS) de plântulas obtidas de sementes de Poecilanthe parviflora, (lote JABOTICABAL) submetidas a germinação em diferentes temperaturas.
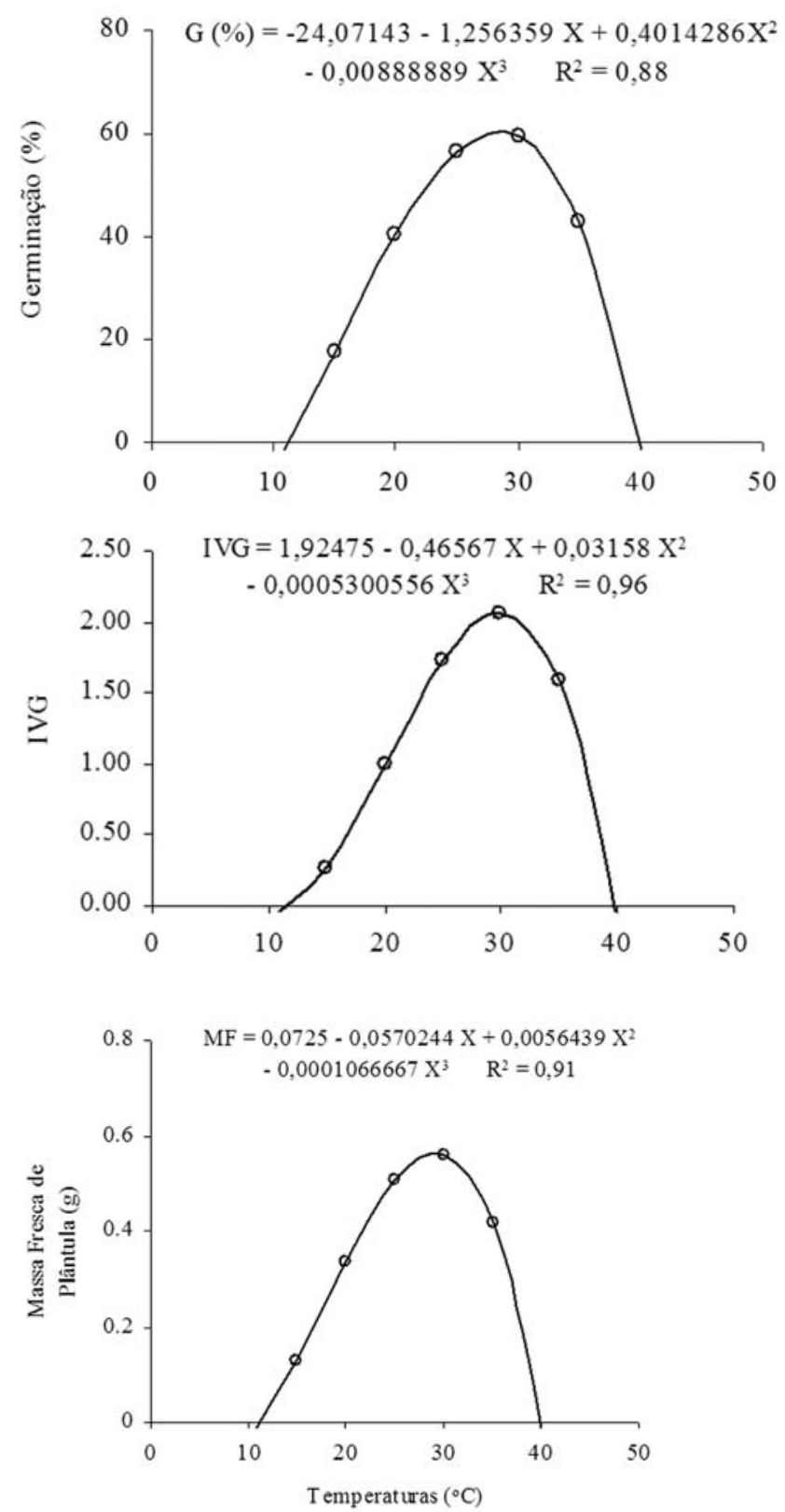
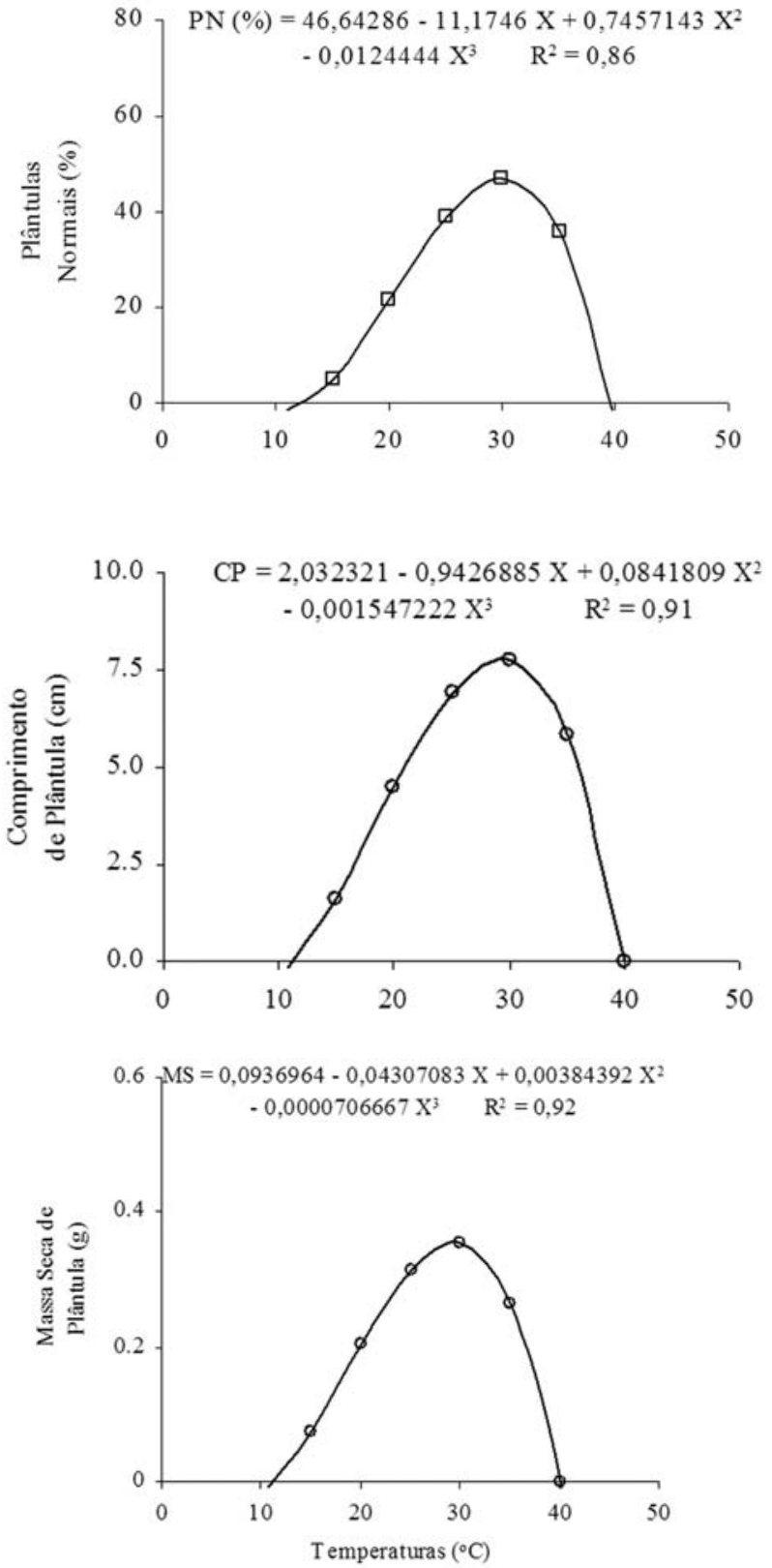
Na Tabela 2 são apresentados os resultados da análise de variância para o teste de germinação dos três lotes de sementes de Poecilanthe parviflora conduzidos a $25^{\circ} \mathrm{C}$ e 20 $30^{\circ} \mathrm{C}$. Houve diferença significativa entre os lotes estudados para todos os caracteres avaliados e efeito significativo de temperatura sobre G, IVG e PN. A interação lote x temperatura foi significativa apenas para germinação $(G)$.

TABELA 2. Resumo da análise de variância e médias de germinação (G, \%), índice de velocidade de germinação (IVG), plântulas normais (PN, \%) e comprimento (CP, cm), massa fresca (MF, g.plântula-1) e massa seca (MS, g.plântula $\left.{ }^{-1}\right)$ de plântulas provenientes de três lotes de sementes de Poecilanthe parviflora, submetidos à germinação em duas temperaturas.

\begin{tabular}{|c|c|c|c|c|c|c|c|}
\hline \multicolumn{2}{|l|}{ Fonte de } & \multicolumn{6}{|c|}{ Quadrados Médios } \\
\hline Variação & GL & $\mathrm{G}$ & IVG & $\mathrm{PN}$ & $\mathrm{CP}$ & MF & MS \\
\hline Lote (L) & 2 & $3764,667 * *$ & $4,8267 * *$ & $3794,00 * *$ & $14,8393 * *$ & $0,7609 * *$ & $0,0360 * *$ \\
\hline Temperatura (T) & 1 & $240,667 * *$ & $7,0092 * *$ & $486,00 *$ & $0,1066^{\mathrm{ns}}$ & $0,0168^{\mathrm{ns}}$ & $0,0002^{\mathrm{ns}}$ \\
\hline $\mathrm{L} \times \mathrm{T}$ & 2 & $280,667 * *$ & $0,0969^{\mathrm{ns}}$ & $122,00^{\mathrm{ns}}$ & $0,1788^{\mathrm{ns}}$ & $0,0110^{\mathrm{ns}}$ & $0,0003^{\mathrm{ns}}$ \\
\hline Erro & 18 & 46.444 & 0.1236 & 73.55 & 0.8905 & 0.0093 & 0.0003 \\
\hline Média & & 72 & 2,245 & 65 & 8,84 & 0,802 & 0,378 \\
\hline \multirow[t]{2}{*}{$\mathrm{CV} \%$} & & 9,48 & 15,66 & 13,29 & 10,67 & 12,07 & 5,09 \\
\hline & & \multicolumn{6}{|c|}{ Médias } \\
\hline Lotes & JABOTICABAL & $52 \mathrm{c}$ & $1,478 \mathrm{c}$ & $46 \mathrm{c}$ & $7,58 \mathrm{c}$ & 0,519 c & $0,320 \mathrm{c}$ \\
\hline \multirow{4}{*}{ Temperaturas } & USM & $95 \mathrm{a}$ & $3,031 \mathrm{a}$ & $88 \mathrm{a}$ & 10,29 a & $1,130 \mathrm{a}$ & 0,451 a \\
\hline & SEMEX & $69 \mathrm{~b}$ & $2,225 \mathrm{~b}$ & $59 \mathrm{~b}$ & $8,66 \mathrm{~b}$ & $0,757 \mathrm{~b}$ & $0,362 \mathrm{~b}$ \\
\hline & $25^{\circ} \mathrm{C}$ & $75 \mathrm{~A}$ & $2,785 \mathrm{~A}$ & $69 \mathrm{~A}$ & $8,78 \mathrm{~A}$ & $0,775 \mathrm{~A}$ & $0,381 \mathrm{~A}$ \\
\hline & $20-30^{\circ} \mathrm{C}$ & $69 \mathrm{~B}$ & $1,704 \mathrm{~B}$ & $60 \mathrm{~B}$ & $8,91 \mathrm{~A}$ & $0,828 \mathrm{~A}$ & $0,375 \mathrm{~A}$ \\
\hline
\end{tabular}

** Valor significativo pelo teste $\mathrm{F}(\mathrm{P} \leq 0,01)$.

* Valor significativo pelo teste $\mathrm{F}(\mathrm{P} \leq 0,05)$.

${ }^{\text {ns }}$ Valor não significativo pelo teste $\mathrm{F}(\mathrm{P}>0,05)$.

Médias seguidas por uma mesma letra, minúscula para lotes e maiúsculas para temperaturas, não diferem entre si (P $>0,05)$ pelo teste de Scott-Knott.

O coeficiente de variação variou de 5,09 para MS a 15,66\% para o IVG. O lote denominado USM apresentou as maiores médias para todos os caracteres avaliados, seguido pelo lote SEMEX e, por último, pelo lote JABOTICABAL que apresentou as médias menores.

A temperatura de $25^{\circ} \mathrm{C}$ proporcionou maiores valores de G, IVG e PN, comparativamente à temperatura alternada de $20-30^{\circ} \mathrm{C}$. Para $\mathrm{CP}, \mathrm{MF}$ e MS não houve diferença entre as duas temperaturas estudadas.

Borges e Rena (1993) citam que a faixa de temperatura entre 20 e $30^{\circ} \mathrm{C}$ é adequada à germinação da maioria das espécies tropicais. Acrescentam, ainda, que determinadas espécies, notadamente as pertencentes aos estágios iniciais da sucessão secundária, germinam melhor sob temperaturas alternadas.

Pela Tabela 3, observa-se que a $20-30^{\circ} \mathrm{C}$, houve a separação dos lotes em três classes de qualidade (USM de melhor qualidade; SEMEX de qualidade intermediária, e
JABOTICABAL de qualidade inferior) e a temperatura de $25^{\circ} \mathrm{C}$ separou os lotes em duas classes (USM de melhor qualidade, e SEMEX e JABOTICABAL de qualidade inferior). A temperatura mais indicada para o processo germinativo é a temperatura constante de $25^{\circ} \mathrm{C}$, pois nesta temperatura os três lotes apresentaram maior germinação. O lote de melhor qualidade fisiológica (USM) apresentou o mesmo desempenho ( $95 \%$ de germinação) nas duas temperaturas estudadas $\left(25^{\circ} \mathrm{C}\right.$ e $\left.20-30^{\circ} \mathrm{C}\right)$, comprovando a qualidade fisiológica superior deste lote, pois, lotes de sementes de melhor qualidade são menos exigentes, dentro de certos limites, quanto às condições para o processo germinativo. O lote JABOTICABAL apresentou menor porcentagem de germinação ( $42 \%)$ na temperatura alternada de $20-30^{\circ} \mathrm{C}$, e melhor desempenho na temperatura de $25^{\circ} \mathrm{C}$, com $62 \%$ de germinação, o que caracteriza a preferência deste lote pela temperatura ótima. Lotes de qualidade inferior apresentam exigências mais específicas para que o processo germinativo ocorra de forma ótima. Os outros lotes (USM e SEMEX) não apresentaram diferença significativa, quanto às médias, entre as duas temperaturas. Observa-se, ainda, que 
a $25^{\circ} \mathrm{C}$, os lotes JABOTICABAL e SEMEX apresentaram desempenhos semelhantes, comprovando que o teste de germinação conduzido sob condições ótimas em laboratório iguala lotes de sementes com potencial fisiológico distinto.

TABELA 3. Desdobramento da interação Lote $X$ Temperatura para germinação de sementes de Poecilanthe parviflora, provenientes de três lotes submetidos à germinação em duas temperaturas.

\begin{tabular}{lcc}
\hline & \multicolumn{2}{c}{ Temperaturas } \\
\hline Lotes & $25^{\circ} \mathrm{C}$ & $20-30{ }^{\circ} \mathrm{C}$ \\
JABOTICABAL & $62 \mathrm{~A} \mathrm{~b}$ & $42 \mathrm{~B} \mathrm{c}$ \\
USM & $95 \mathrm{~A} \mathrm{a}$ & $95 \mathrm{~A} \mathrm{a}$ \\
SEMEX & $68 \mathrm{~A} \mathrm{~b}$ & $69 \mathrm{~A} \mathrm{~b}$ \\
\hline
\end{tabular}

Médias seguidas por uma mesma letra, maiúscula na linha e minúscula na coluna não diferem entre si $(\mathrm{P}>0,05)$ pelo teste de Scott- Knott.

\section{CONCLUSÕES}

O teste de germinação para sementes de Poecilanthe parviflora pode ser conduzido nas temperaturas constantes de $25^{\circ} \mathrm{C}$ ou $30^{\circ} \mathrm{C}$ ou alternada de $25-35^{\circ} \mathrm{C}$.

\section{REFERÊNCIAS}

ALVES, E.U.; PAULA, R.C.; OLIVEIRA, A.P.; BRUNO, R.L.A.; DINIZ, A.A. Germinação de sementes de Mimosa caesalpiniefloia Benth em diferentes substratos e temperaturas. Revista Brasileira de Sementes, Brasília, DF, v.24, n.1, p.169-178, 2002.

ARAÚJO NETO, J.C.; AGUIAR, I.B.; FERREIRA, V.M. Efeito da temperatura e da luz na germinação de sementes de Acacia polyphylla D.C. Revista Brasileira de Botânica, São Paulo, v.26, n.2, p.249-256, 2003.

BORGES, E.E.L.; RENA, A.B. Germinação de sementes In: AGUIAR, I.B.; PIÑA-RODRIGUES, F.M.C.; FIGLIOLIA, M.B. (Coord.). Sementes florestais tropicais. Brasília, DF: ABRATES, 1993. p.83-135.

BRASIL. Ministério da Agricultura. Regras para análise de sementes. Brasília, DF: SNDA, DNPV, 1992. 365p.

CARVALHO, P.E.R. Espécies arbóreas brasileiras. Brasília, DF: Embrapa Florestas, 2003. p.407-411.
CARVALHO, N.M.; NAKAGAWA, J. Sementes: ciência, tecnologia e produção. 4. ed. Jaboticabal: FUNEP, 2000. 588p.

KRAEMER, K.H.; KAMPF, A.N.; ÁQUILA, M.E. Luz e temperatura na germinação de sementes de Tibouchina urvilleana. RevistaBrasileiradeHorticultura Ornamental, Campinas, v.6, n.1/2, p.39-45, 2000.

LEAL FILHO, N.; BORGES, E.E.L. Influência da temperatura e da luz na germinação de sementes de canudo de pito (Mabea fistulifera Mart). Revista Brasileira de Sementes, Brasília, DF, v.14, n.1, p.57-60, 1992.

LORENZI, H. Árvores brasileiras: manual de identificação e cultivo de plantas arbóreas nativas do Brasil. Nova Odessa: Ed. Plantarum, 1992. p.225.

MAGUIRE, J.D. Speed of germination - aid in selection and evaluation for seedling emergence and vigor. Crop Science, Madison, v.2, n.1, p.176-177, 1962.

NAKAGAWA, J. Testes de vigor baseados no desenvolvimento das plântulas. In: KRZYZANOSWSKI, F.C.H.; VIEIRA, R.D.; FRANÇA NETO, J.B. (Ed.). Vigor de sementes: conceitos e testes. Londrina: ABRATES, 1999. cap.2, p.2-24.

PEREZ, S.C.J.G.A.; MORAES, J.A.P.V. Influência da temperatura, da interação temperatura-giberelina e do estresse térmico na germinação de Prosopis juliflora (Sw.) DC. Revista Brasileira de Fisiologia Vegetal, Brasília, DF, v.2, n.1, p.41-53, 1990.

PINTO, J.R.R. Levantamento florístico, estrutura da comunidade arbóreo-arbustiva e suas correlações com variáveis ambientais em uma floresta de vale no parque Nacional da Chapada dos Guimarães, Mato Grosso, 1997. 85f. Dissertação (Mestrado). Universidade Federal de Lavras, Lavras.

RANDI, A.M.; FELIPE, G.M. Efeito da temperatura, luz e reguladores de crescimento na germinação de Stevia rebaudiana Bert. Ciência e Cultura, São Paulo, v.33, p.404411, 1981.

SANTOS, S.R.G.; AGUIAR, I.B. Germinação de sementes de branquilho (Sebastiania commersoniana (Bail.) Smith e Downs) em função do substrato e do regime de temperatura. Revista Brasileira de sementes, Brasília, DF, v.22, n.1, p.120-126, 2000.

SOUZA, C.V.; LORENZI, H. Botânica sistemática: guia ilustrado para identificação das famílias de Angiospermas da flora brasileira, baseado em APG II. Nova Odessa: Instituto Plantarum, 2005. p.325. 